\title{
Information Technology Education in Papua New Guinea: Cultural, Economic and Political Influences.
}

\author{
Limbie Kelegai and Michael Middleton \\ School of Information Systems, Queensland University of Technology \\ Brisbane, Australia
}

I.kelegai@student.qut.edu.au m.middleton@qut.edu.au

Executive Summary

Information and Communication Technology is the driving force in the information intensive global society. Information Technology (IT) professionals with skills and capabilities required by the IT industry are scarce. Industry and policy makers see education institutions as the vehicle to produce skilled IT professionals to bridge the gap between the changing technology and industry needs. Many Least Developed Countries including Papua New Guinea are slowly coming to grips with the rapidly changing IT industry and need for IT education and development.

The lack of information policy guidelines in many instances hinders the growth of IT industry in many LDCs. Also there are issues and factors that influence IT education in developing countries especially Papua New Guinea. These include cultural and language impacts on IT education in PNG. Preliminary results from our recent study indicate that PNG IT professionals place a high emphasis on non-technical skills.

In this paper we examine a number of social, cultural and industry factors that influence IT education, and postulate several principles that are useful in developing an IT education model suitable for LDCs.

Keywords: IT/IS education, Least Developed Countries, IT/IS Education model, IT/IS Curriculum, Cultural Factors, Information policy, IT industry

\section{Introduction}

Rapid and continuous changes in information and communication technologies have produced shortages of Information Technology (IT) professionals throughout the world, particularly in Least Developed Countries (LDCs). These changes may mean that an individual's competence quickly becomes outmoded. Policy makers, who see the education system as the vehicle by which IT professionals are trained and prepared to meet industry needs, must have confidence that educational institutions are able to produce people to meet the demands of the changing world. The availability of human resources is still the most important element in IT diffusion.

Material published as part of this journal, either on-line or in print, is copyrighted by the publisher of the Journal of Information Technology Education. Permission to make digital or paper copy of part or all of these works for personal or classroom use is granted without fee provided that the copies are not made or distributed for profit or commercial advantage AND that copies 1) bear this notice in full and 2) give the full citation on the first page. It is permissible to abstract these works so long as credit is given. To copy in all other cases or to republish or to post on a server or to redistribute to lists requires specific permission and payment of a fee. Contact Editor@JITE.org to request redistribution permission.
IT professionals in industry, and educators, may neglect to consider each other's perspective of the workplace. Employers argue that university graduates possess general computing knowledge, but lack specific skills that industry requires. IT professionals are required to possess a distinct blend of technical and non-technical skills, business orientation, and attention to customer service to be 
successful. Educators place an emphasis on theory, problem solving, and analytical skills.

Students in Papua New Guinea (PNG) are raised in different cultural backgrounds compared to those of Western Countries. As such they may have different perceptions and values that influence skills/knowledge development. Factors such as culture, gender and life history seem to affect students' view of IT as a field of study and work, and these factors may also affect the development of IT/IS skills.

We have been investigating IT curriculum requirements in PNG, and as part of that process have made a number of observations about the influence of cultural factors on IT education. Here we discuss social, economic and political issues that influence educating and developing IT professionals in LDCs and make particular reference to Papua New Guinea. These lead us to state a number of principals that appear appropriate for PNG IT education policy, and which may have application in other LDCs.

\section{Background}

\section{Geography}

PNG is an island nation north of Australia from which it became independent in 1975. It is a parliamentary democracy with a single legislature, the National Parliament, through elected members. Elections are held every 5 years for the 109 seats: 20 regional and 89 open electorates. It is an LDC with a small but slowly developing IT industry and relies on technology imported from other countries. PNG has cultural norms that are different to other countries. Like other LDCs, PNG's unstable political environment is one of the major hindrances to economic growth. Of its 4.5 million people, $85 \%$ live in rural areas. Overall there is a population density of 8 persons per square kilometer. The annual population growth rate is estimated at 2.4 percent. PNG has more languages (over 800) than any other country in the world, with the possible exception of India. The official language is English with Pidgin and Hiri Motu being used widely as lingua franca to facilitate communication among people of diverse linguistic backgrounds.

\section{IT Workforce}

There is wide shortage of IT professionals throughout the world, particularly in LDCs. In PNG the demand far outweighs their current availability. Computer systems and software are rapidly becoming outdated, making an individual's knowledge quickly obsolete. Policy makers generally see the education system as the vehicle by which IT professionals are trained and prepared to meet industry needs.

Emphasis is now placed on educational institutions to produce IT professionals to meet the demands of the changing workplace. Third world countries have been slower in realizing the significance of human resources development, in particular for IT, in order to become a part of the global context. In PNG, IT development and change is slow due to issues such as lack of funding, lack of adequately qualified teaching staff, lack of government support in terms of policy guidelines, and inadequate infrastructure.

IT professionals in industry and educators may function with little reference to each other, each group having a different perspective of the workplace. It is common for employers to argue that university graduates possess general computing knowledge but lack specific skills that industry requires (Pham, 1997). Educators argue that in skills and competency-based programs, graduates' scope for learning is narrowed, as the programs often lack fundamental and analytical knowledge, and function at an abstract level. Furthermore, educators advocate that the main goal of higher education is not vocational training where the focus is to produce specialized and skilled IT professionals, but a wider context that includes emphasis on theory and research. For example, a respondent to our investigation's follow-up interviews was concerned that, 'the danger with industry collaboration is that teaching and learning will be nar- 
rowed to specific product needs. Students should learn a wide range of skills'. Developing curriculum by educators in collaboration with industry in PNG can narrow this gap although it may never be completely bridged.

Education and learning is important to underpin the country's information economy. It is essential that the government and private sector ensure appropriate skills are taught through tertiary education and onthe-job training to meet industry needs. The demand for personnel with IT knowledge, experience and qualifications from the workplace is growing rapidly, as the workplace is gradually applying computing skills to improve efficiency. PNG nationals urgently require IT education and training from educational institutions to meet the country's increasing needs.

\section{Culture}

Korpela (1996, p.30) defines culture as 'narrowly referring to a complex of values, norms, ideas and customs, shared by a group or society, distinguishable from the culture of another group'. For Hofstede (1983, p.23) it is a 'collective programming of the mind which distinguishes the members of one group from those of another'. In this context culture deals with a collective way of thinking by group of people.

Each society arrives at its answers as a consequence of these fundamental issues, which represent the common element of structure in the cultural system of the country. Hall (1977) classified culture in two contexts, high context and low context. High context societies are characterized as collectivist, while low context societies are individualist. The characteristics of Hofstede's four underlying dimensions are also identified in Hall's classifications. Hofstede noted that nations could be classified in four underlying dimensions as follows:

- Individualism/Collectivism

Individualist societies have loosely knit social structure where individualist approaches are encouraged. Collectivist societies prefer tightly knit social framework where in-group, clan or organization ideals take precedent. Individuals can expect clan in groups or relatives to consider their needs, loyalty being a virtue emphasized. This measures the 'degree of interdependence a society maintains among individuals'.

- Large/Small Power Distance

This measures the extent to which the members of a society accept that power is distributed unequally. LPD has a hierarchical order in which everyone has his/her place with no justification. SPD societies strive for power equalization and demand justification for power inequality. This classification relate to how society handle inequality when it occurs.

- Strong/Weak Uncertainty Avoidance

This measures the degree to which members of societies feel uncomfortable with uncertainty and ambiguity. Strong UA societies are less tolerant to deviant ideas and maintain rigid code of belief and ethics. Weak UA societies are more tolerant to deviance and are open to new ideas.

- Masculinity/Femininity

Masculine society prefers achievements, heroism assertiveness, and materialism and is less caring with an individualist approach. Femininity emphasises relationship, modesty and quality of life.

Most LDCs score closer to collectivism, while Western Countries score closer to individualism (Hofstede, 1997). PNG is regarded as a collectivist culture. However western ideologies from colonization are slowly changing many LDC cultures, including that of PNG. Collectivism's particular features in PNG, influence uptake of IS and IT. For example, when the banks in PNG recently introduced ATM 
banking facilities, many customers refused to change from their passbook accounts to ATM cards. This can be attributed to the strong Uncertainty Avoidance societies where members feel uncomfortable with uncertainty and are less tolerant to out of the ordinary ideas. Although the banks imposed fines, the change over was slow and in some cases there is little progress.

\section{Features of the PNG IT Environment}

There are a number of matters that have direct bearing on IT education policy for which we can compare some general assumptions about LDCs with the particular situation in PNG. Our main interest in this paper is cultural factors, however there are a number of relevant features of the IT environment that are influential in addition to the intrinsic cultural factors, and we will include these in preliminary discussion. From these features we educe a number of principles for IT education that we summarize leading to our conclusion.

\section{Education}

In many LDCs there are no or few primary or secondary schools with computers. In PNG, IT education and training has not been formally introduced in primary and secondary schools. A significantly high percentage of the population, including students, has limited IT literacy and computer knowledge. The majority of the students enrolled into tertiary institutions may have little or no knowledge or experience with computers.

In contrast to the above, students in DCs are introduced to computers at an early age (primary education level) at home or in primary schools, which accelerate the learning process. For example, in Finland, the largest part of its GNP is invested for the education system. Learning skills, literacy and attitude towards learning, all arguably important factors in achieving success in adopting IT, are well developed. Computers were introduced there into primary and secondary school in 1980.

In the United States, Canada, Australia, and in most of Europe, where computers were introduced to primary, secondary and tertiary institutions years ago, IT-based educational tools have been used significantly to support learning. When students reach university entry level they have developed computer skills and are IT literate. Advancing ASEAN (Association of South-East Asian Nations) countries like Singapore place an emphasis on IT literacy and education. Sinebare (1999) cites Singapore as one example of a Newly Industrialized Country (NIC), and differentiates NICs from laissez-faire DCs. He maintains that IT applications in the latter have been ad hoc because there has been no formal IT or industry policy, and because no formal structure has been established to implement such a policy. Both computer education and computer studies curricula have been left to chance.

Most students in PNG are not introduced to computers until at tertiary education level. However, recently individual schools in PNG are introducing and incorporating computers in the school curriculum.

\section{Higher Education}

There are 6 universities in Papua New Guinea. They are University of PNG (Port Moresby), PNG University of Technology (Lae), University of Goroka (Goroka), Divinewood University (Madang), University of Vudal (Rabaul) and Pacific Adventist University (Port Moresby). The last three mentioned have recently been upgraded from college to university status.

The PNG University of Technology is the only University in PNG to offer degree courses in information systems and computer science. The university implemented its computer studies course in 1979 as a component of the business studies degree program. It has since been producing graduates majoring in information systems. The computer science degree program was implemented in 1993, and in 1997 saw 
the first graduates (Bampton, 1998). The Department of Mathematics and Computer Science runs the computer science program.

Information and Communication Technologies (ICTs) encourage globalization. Information infrastructure in terms of IT and human resources development should be a priority for PNG if it intends to play a part in the global phenomenon. However, administrators and policy makers alike must share this vision. PNG University of Technology's own vice-chancellor has stated that the University was aware (of the need for) 'competent graduates who can work in a team, be analytical and be adaptable to new situations’ (Kaiulo, quoted by Bampton, 1998).

For PNG to underpin its information economy, it is prudent to develop the intellectual infrastructure through education. Emphasis would be 'the need for educational programmers to constructively adjust curricula in order to remain a relevant force for providing employers (business and public) with better qualified employees' (Thoeuri \& Gunn, 1998, p.103). IT education and curriculum cannot be static because of the constant changes in information technology. Employers have raised concerns regarding the preparedness of entry-level professionals. Poor university programs, lack of ongoing training for employee and the rapid phases of IT, have resulted in the lack of qualified IT personnel.

We consider that curriculum model should have multiple exit and reentry points that encourage industry experience and individual development, as part of orientation to industry needs in differing job classifications. We include this among our later set of principles

\section{IS/IT curriculum}

The importance and role of developing better curriculum is significant in bridging the gap between the changing technology and industry needs. Are developing countries providing the desired education standards for employers? Universities should provide a conducive learning environment and industry oriented curriculum that the business community perceived as meeting their IT requirements.

Curricula are developed with the objective of producing skilled and employable graduates. Ching et al (2000) state that employability rests in the knowledge and skills imparted upon them through their education. In recent years there has been a significant re-orientation of IS curricula to provide for managing and facilitating. Organizational skills such as communication and understanding business have become increasingly significant (Leitheiser, 1992; Ching et al, 2000; Letch \& Randolph, 2000). Emphasis for a balanced approach for technical and organizational skills may be relevant for IT/IS professionals in PNG, as is continual updating of curriculum. A respondent to our survey follow-up interviews, commented upon lack of teaching staff and administrative difficulties in updating the curriculum

Several external factors determine how an organization applies IT (Leitheiser, 1992, Porter, 1985). Factors such as the availability of technology, organizational requirements, service need and requirements determine the need for IS skills. The challenge for academia is to understand the factors that influence IT, and how these factors shape the needs of the skill set in PNG. The skill set may be accommodated within the IS curricula to prepare graduates to meet industry needs.

The designing of quality IS curriculum may influence the quality of IS graduates. IT is changing constantly; therefore a dynamic curriculum framework is required to cater for the changes. Some DC universities have developed or adopted curriculum models such as IS '97 (Association for Computing Machinery \& Association for Information Systems, 1997), which is based on undergraduate degree programs in the USA and Canada. ACM also has computer science and data processing models. These models may be inappropriate for PNG since student entry level and program background are not relevant. Also there are other issues such as finance, subject expertise and technical resources, political, social, cultural and economical instabilities that hinder full adoption. However a refined version of the curriculum models suitable for local conditions could be implemented. 
The IT industry is constantly evolving at all levels. As with other curricular models such as IS '97 we consider that the IS curriculum should have a control and audit mechanism that will constantly provide feedback for review. (Item 6 in our summary of IT education principles).

\section{Information as a Resource in PNG}

With the implementation of ICT there is increased and exponential growth in the production and dissemination of information in PNG. Government organizations depend very much on the use of relevant information in both their regulatory functions and in providing services to the public. In recent years, with the advance in technology, the publication and storage of information has been growing rapidly, a phenomenon sometimes called the 'information explosion'. Businesses are now being conducted on a global scale. Today information is recognized as an economic resource. With the increase in information, there is need for coordination between the different sectors of the economy in producing and disseminating information goods and services.

There is a need for PNG to develop its information infrastructure to function globally. If there is infrastructure in LDCs, it is limited to small regions, usually in the capital cities. Therefore, most third world countries emphasize the need to develop information infrastructure (Cornella, 1998; Audenhove et al, 1999). Guidelines for development of information resources, or implementation of information policy, are rudimentary.

The vision of a company, organization or country is the courageous idealization of what the company, organization or country aspires to achieve in the future. The success of any IT vision rests on maintaining a competent base of IT professionals with strong technical capabilities (Loh et al, 1995). For this reason, education and human resource development are singled out first in most IT policy frameworks (Karlsson, 1996; Loh et al, 1995). In most LDCs there is economic and political instability, resulting in an economic environment less conducive to IT growth. Political leadership is also important in the process, in order to initiate projects and follow up implementation in relation to a country's vision or policy. Among our respondents, there was strong expression about lack of government direction and leadership in creating a clear framework for IT growth in PNG. Therefore we consider that an IT curriculum model should be planned, coordinated and developed in accordance with the country's IT, Education, and Economic policies. (This is included as item 2 in our summary of principles at end).

\section{Information Policy}

Cornella (1998, p.3) describes information policy as a 'set of public sector laws, regulations and policies that encourage, discourage or regulate the creation, use, storage, communication and presentation of information'. Common elements of information policy are: identifying the information needs of the nation, devising ways of achieving these needs, and promoting effective use of the resulting services. Public policy embraces a number of areas that may already be undertaking information policy development within constrained public or private spheres. These areas include communication, libraries, broadcasting, IT, education and training, primary industry, and health services. A combination of policies, acts of parliament, and strategies can form the basis of a national information policy.

Information policy provides a broad framework within which the wide range of information-related activities undertaken by public and private industry can be reconciled. It also covers a wider range of portfolio boundaries, thus recognizing a wider range of policies, principles and practices. Any nation with serious policies for economic, social and cultural development needs complementary policies to ensure the supply and use of information. This approach is crucial, given the universal importance of information and the rapid growth of IT. Information policy will also provide a link and relationship between different policies and cover a wider application of policies in specific areas. Perhaps most importantly, information policy emphasizes the need and importance of drawing towards information intensive infor- 
mation society. The development and implementation of any information policy is not the sole responsibility of the government, but a concentrated and collaborative responsibility on the part of many organizations.

In 1994 the PNG Ministry of Information and Communication formed the Information Technology Board (ITB). Its members comprised experts from a cross section of the information industry. One of the committee's tasks was to develop an information policy for PNG. However, there has not been evidence of policy implementation. Another similar committee has recently been established along the same lines.

\section{IT Industry}

Digital convergence is increasingly tying computer technology to telecommunications and broadcasting. The convergence and fusion of different technologies like media, computers and telecommunication have underlined the urgency for change. For our purposes the PNG IT industry encompasses telecommunications and the electronic media. The IT industry includes the development and application of computers and communications-based technologies for processing, storing and managing data and information; computer hardware and component manufacturing; computer software development and various computer related services; communications equipment and services.

Current industry trends are for growing acceptance of online trading, an expansion of Internet commerce, increased tendency towards small home offices, and an increased demand for client support services. Information storage and retrieval, and network administration are areas in which growth is most anticipated.

In PNG, initiatives are being taken to boost the IT industry. One of these is to liberalize the telecommunication sector (Waieng, 2000). The telecommunications network in PNG is owned by the Government and operated by its statutory organization, the PNG Telikom, which is the sole telecommunications carrier. Infrastructure is limited to major urban centers like Port Moresby, Lae and Mt Hagen. Telecommunication services to the rural population are minimal and unreliable.

The Internet was introduced to PNG in 1997 and currently 5 Internet Service Providers (ISP) provide online Internet and email connections. There is no IT manufacturing industry; however one IT company assembles computers in the country with parts imported from Asia or Australia. Most computer hardware and software are imported from Asian or Australian markets, thus relying on foreign IT industry. Hardware sales increased in recent years; however service and support in most cases are unreliable. Software industry is largely limited to implementing packages purchased off the shelf. IT professionals administer and maintain these systems. However, there were indications from both academia and industry in our interviews, of the continuing importance of programming skills to acquire thinking and analytical skills.

Public sector organizations implement finance, personnel and decision support systems on local or wide area networks. The private sector implements similar systems including process control systems. The banking sector introduced wide area networking for their banking systems throughout the country. As with most developing countries, the high cost of living is a concern for PNG. The cost of telecommunication services, electricity and air travel is extremely high. Telephones and computers are luxury items therefore owned by relatively few people. Thus a significantly small percentage of the population accesses the Internet. Although the impact of Internet is anticipated to be high, its potential is yet to be realized in PNG. As was noted among our respondents, Internet access is minimal and use is limited.

The Internet and related industry in PNG are slowly developing, however only in private and multinational organizations. The public sector is not a major user, and Internet use is hardly found in homes. Apart from a handful of tertiary institutions, Internet services are virtually nonexistent in primary, secondary and tertiary institutions (Waieng, 2000). Any curriculum model should primarily focus on meet- 
ing industry requirements although the opportunity exists for attention to broader requirements including global perspectives. We consider that an IT education model should be focused to cater for the IT industry requirements in the country with a view to expansion in the future. (This is the first of our proposed set of principles summarized before the conclusion).

\section{Technology Leapfrogging}

It is often argued that latecomers in telecommunication are better placed. LDCs are able to learn from mistakes by DCs and leapfrog to the latest working technology. Technology leapfrogging can act as a key to boost growth rates and improve competitiveness. Leapfrogging happens when implementing a new and up-to-date technology in an application area, in which at least the previous version of that technology has not been deployed. Especially with the presence of multinational companies, latest technologies are introduced to PNG. For example, rural parts of PNG have seen telecommunication move from nothing to a satellite based system and availability of Internet café in a single leap (Davidson et al, 2000).

PNG may passively adopt technology as standard products which have been developed in industrialized countries, and which can be usefully employed immediately. However it requires technical expertise to implement and maintain the new technologies. There is a lack of experience and limited past experience. These skills need to be developed in PNG.

\section{PNG Cultural Factors}

In our ongoing study (Kelegai \& Middleton, 2000) IT professionals were requested to identify the cultural factors that influenced their tertiary education. For instance in PNG there are closely knit communities. In these communities, minors rarely question their parents and elders, and knowledge imparted by the elders is readily accepted. However, students at tertiary level are expected to actively participate, question and debate issues with the teachers. We intend to identify if the graduates' diverse social and cultural backgrounds influence their education, particularly for IT graduates.

Generally students adapted well to the university environment, with assistance from their regional or ethnic groups. The education system prepares students for university, however, cultural attachment by students with regional and ethnic groups, is a concern for the PNG universities. In the social context, there are many instances of fighting among students within these groups. For example, a respondent indicated that in the learning environment, groups like these dominate and deprive others of the use of teaching resources.

Collectivist societies are face-conscious, and losing face is far more humiliating and painful then other treatment. Students hesitate to speak up in large groups and in particular in classes. Bampton (1998, p.26) while teaching in PNG noted the 'unnerving situation with students' respectful silence and refusal to ask questions nor speak in lectures'. Students do not respond to questions for fear either of a wrong answer or a right answer (Hofstede, 1997; Mestre, 2000; Bampton, 1998). For example one of our interviewed respondents, now an IT professional summarized a general view thus 'No..No, I never questioned the teacher and only participated when asked to'. Class contribution and participation was always complimentary to the teachers and never against them.

In the classroom environment students are expected to respect teachers as a source of knowledge and wisdom, and never dispute what is presented (Hofstede, 1997; Bampton 1998; Talbert-Johnson \& Beran, 1999). Teachers are regarded as gurus in the subject area they are teaching. Hofstede (1997, p.11) states that 'students from strong uncertainty avoidance countries expect their teachers to be the experts who have all the answers', and expect structured learning situations. This may have two possible effects. Firstly 'students foster reliance, inhibit independence and growth of inductive reasoning and nurture in- 
activity and submission' (Mestre, 2000, p.3). Secondly, with no criticism or challenge from students, teachers are not able to critically analyze their work and presentation. Students remain dependent on teachers even after reaching higher education level (Hofstede, 1997).

In contrast in lower power distance cultures, parents at home, teachers at school and at workplace, encourage independence.

PNG students learn in English, a $3^{\text {rd }}$ or $4^{\text {th }}$ language. Understanding each other can be extremely difficult, especially with instructors where English is their $2^{\text {nd }}$ or $3^{\text {rd }}$ language. In the cultural context, a greater level of communication skills is required because cultural differences create dissimilar meanings and expectations. Communication and learning are adversely affected when intercultural cues between students and teachers are not understood. Among our respondents, concern was expressed that many lecturers are recruited from overseas despite their English language deficiency. Course delivery and interaction between student to staff and staff to staff can be adversely affected.

A small number of indigenous IT professionals are in academia in PNG. IT instructors comprise mostly expatriate staff, compensating for inexperience or lack of expertise in the country. Most indigenous staff complete their undergraduate program in the country and later undertake postgraduate studies overseas. Remuneration packages for expatriate staff are higher than the indigenous staff. This disparity is a concern to local staff, who may be troubled by the inequities (Talbert-Johnson \& Beran, 1999). Recently in PNG, national academic staff at one tertiary institution resorted to industrial action calling for better remuneration packages equivalent to expatriate staff. Salary and conditions are not attractive for both local and expatriate staff. This is reflected in unavailability of expertise to teach in the specialist IS courses. Inexperienced staff are recruited to teach in the subject areas unfamiliar to them. In doing so, universities may be producing graduates who are not meeting industry requirements. IT is embedded in the social, organizational, political and cultural settings and influences these settings. Therefore we postulate that curriculum designers should take account of such issues as a principle of IT education.

\section{Discussion}

Given the characteristics of a collectivist society, collaborative and cooperative learning environment may be the appropriate structure of learning for students from collectivist cultures (Mestre 2000; Hofstede, 1997; Haggerty \& Neufeld, 2000). In pedagogical terms, objective learning theory may be compared with constructivism. Objective learning theory emphasizes the notion that knowledge exists, has an objective reality, and may be transferred to the learner. The efficient and effective transmission of this knowledge is the objective of a suitable instructional design, such as by lecture method and teachercentered learning.

Constructivism in contrast, states that each learner, according to the learner's perceptions of reality, constructs knowledge. Individuals learn through interaction with other learners, instructors and material content. 'The instructional methods are case studies, group work, debate, simulation, group problem solving activities and team based learning' (Haggerty \& Neufeld, 2000, p.153). It appears that a constructivist approach may be the more fruitful one in a collectivist culture.

Addressing curriculum review and update within a planned time frame is necessary considering the rapid changes in IT. IS/IT professionals are required by industry to possess skills and capabilities to meet their needs.

Recently, we initiated a study to determine employers', educators' and IS/IT professionals' perceptions of the identified skills and capabilities required by IS/IT graduates in PNG. This included a three-part survey that was developed and distributed to employers, IT professionals and educators in PNG. Part 1 of the instrument identified demography and academic details. Part 2 was a 74 point required skills/capabilities set developed using currently proposed curricula recommendations (Association for 
Computing Machinery \& Association for Information Systems, 1997), and instruments from similar studies (Snoke \& Underwood, 1998; Letch \& Randolph, 2000; Doke \& Williams, 1999; Landry et al, 2000; Morris \& Bartczak, 2000).

A set of skills/knowledge capabilities was abstracted and reworded for the purpose of the study. Responses to each skill/capability were rated according to the respondents' perceived importance and scored by assigning numeric values on a scale of 1 (extremely unimportant) to 7 (extremely important) (Kelegai \& Middleton, 2000). Part 3 determined information about respondents' organization and information system infrastructure in these organizations. Table 1 shows the skill groups (aggregated from the 74 factors identified) ranked according to perceived importance. The results are based upon the responses to date of the IT Professionals cohort (55 responses; 25\% rate). The responses indicate that PNG

IT professionals place a high

\begin{tabular}{|lcc|}
\hline Skill Groups & $\begin{array}{c}\text { Importance } \\
\text { (Wt. Average) }\end{array}$ & $\mathrm{Sd}$ \\
\hline Non-technical (Soft skills) & 5.25 & 1.20 \\
Interpersonal Skills & 5.16 & 1.17 \\
General IS Skills & 4.82 & 1.18 \\
Business related skills & 4.79 & 1.22 \\
Networking Skills & 4.51 & 1.20 \\
Programming and Software Skills & 4.50 & 1.17 \\
Operating Systems Skills & 4.26 & 1.38 \\
\hline
\end{tabular}

Table 1: Skill groups aggregate Weighted Average rating emphasis on non-technical (or 'soft') and interpersonal skills.

Results also indicate that operating systems and programming language groups (technical skills) scored a relatively low rating. Weighted average was calculated by determining the sum of frequencies of each scale in each skill group question multiplied by the weight (1-7) and divided by the sum of responses.

The results correspond to similar studies conducted in the USA and Australia (Von Hellens et al, 2000). Despite the significant differences between USA, Australia and a LDC like PNG, the results indicate common perceptions. For example, non-technical skills was given the highest ranking followed by personal skills in the study by Von Hellens et al, (2000). Technical skills groups, programming and operating skills were given relatively low rankings.

With the possibility of liberalization of the telecommunication market, growth is anticipated in IT and new business prospects and processes are anticipated on the Internet. Trends in IT include the deployment of new technology influencing changes in business process, emphasis for on-line marketing and network technology. Investments in mining and oil exploration by multinational organizations bring new technology and demand for IT professionals.

Also primary, secondary and national higher education curriculum reforms will include IT as a significant tool and teaching resource for education. Educational policy direction and reforms are currently being reviewed in PNG.

In PNG, a survey was last conducted in 1988 to determine industry requirements for the IS curriculum at the PNG University of Technology (Salt, 1988). A review of the course was than initiated and a new course structure was developed and implemented based on the ACM 78 curriculum model. Alterations were made to the course over the years to cater for the changing industry needs in PNG. The 'IS 78' model was superseded by 'IS 97' (which is currently under review to be upgraded to 'IS 2000' model). Among our respondents, concern was expressed about the lack of substance in the curriculum content, and that academics were teaching units not specified in the syllabus approved by the University's academic board. 


\section{IT Education Principles}

We discussed a number of issues related to IS/IT education in PNG. Given the preceding discussion, we highlight several principles that provide a foundation for the IT Education Model suitable for PNG and other LDCs with similar social, political, economical and cultural settings.

1. The IT education model should primarily be focused to cater for the IT industry in the country.

2. It should be planned, coordinated and developed in accordance with IT; Education; and Economic policy

3. It should plan to produce skilled IT professionals meeting industry needs in the different job classifications.

4. It should have multiple exit and reentry points that encourage industry experience and individual development.

5. It should consider social and cultural issues in the curriculum design.

6. It should have a control and audit mechanism that should constantly provide feedback for review.

\section{Conclusion}

The IT industry is slowly but steadily developing in PNG. Strategic issues such as information policy guidelines, national infrastructure, and economic and political stability, must be addressed. It is common for LDCs to implement the latest technology to be compatible with the rest of the world, with no or little local expertise to implement and maintain the systems.

There is increasing demand for IT professionals throughout the world, and PNG is no exception. Universities are required to produce IT graduates to meet the demand. Emphasis is for universities to provide a curriculum appropriate for industry requirements in PNG, and create a suitable academic environment for students to acquire the relevant skills.

IT students in PNG are raised in different cultural backgrounds and encounter learning difficulties in areas such as class participation, language, and 'parental association' with the teachers. Classroom learning may be enhanced by a collaborative learning environment, according to the framework of constructivist learning theory.

We look forward to more research that determines cultural and other related issues faced by IT professionals at their workplace.

\section{References}

Audenhove, L., Burgelman, G., Nulens, G., \& Cammaerts, B. (1999). Information society policy in developing world: a critical assessment. Third World Quarterly, 20, 387-404.

Association for Computing Machinery \& Association for Information Systems (1997). IS ‘ 97 model curriculum guidelines for undergraduate degree programs in information systems. Association for Information Technology Professionals. Retrieved $22^{\text {nd }}$ November, 2001 from World Wide Web: http://www.acm.org/education/curricula.html

Bampton, A. (1998). Teaching computer science in PNG. In ITiCSE '98, Proceedings of the 6th annual conference on the teaching of computing $/ 3^{\text {rd }}$ annual conference on integrating technology into computer science education (pp.25-27). Dublin: ACM. Retrieved $6^{\text {th }}$ March, 2001 from ACM Digital Library portal on the World Wide Web http://portal.acm.org/portal.cfm

Ching, R.K, Glorfled, L.W., \& Lam, M. (2000). Integrating the IT/IS professional community with IT/IS academic programs. In Americas Conference on Information Systems: AMCIS 2000. Long Beach, CA, USA: AMCIS. (AMCIS2000 Proceedings, CD-ROM, 2000). 


\section{IT Education in Papua New Guinea}

Cornella, A. (1998). Information policies in Spain. Government Information Quarterly, 15, 197- 221.

Davidson, R., Vogel, D., Harris, R., \& Jones, N. (2000). Technology leapfrogging in developing countries. The Electronic Journal on Information Systems in Developing Countries, 1, 1-10. Retrieved $5^{\text {th }}$ March 2001, from the World Wide Web http://www.unimas.my/fit/roger/EJISDC/vol1/voll.htm

Doke, E.R., \& Williams, R.S. (1999). Knowledge and skill requirements for information systems professionals: an exploratory study. Journal of IS Education, 10, 10-18. Retrieved $20^{\text {th }}$ August 2000 from JISE on the World Wide Web at http://www.gise.org/JISE/

Haggerty, N. \& Neufeld, D.J. (2000). Collaborative team learning in information systems: a pedagogy for developing team skills. In Americas Conference on Information Systems: AMCIS 2000. Long Beach, CA, USA: AMCIS. (AMCIS2000 Proceedings, CD-ROM, 2000).

Hall, E. T. (1977). Beyond culture. New York: Anchor Press.

Hofstede, G. (1983). Culture and management development. Geneva: UNDP/ILO.

Hofstede, G. (1997). Cultures and organizations: software of the mind. Rev. ed. NY: McGraw-Hill.

Karlsson, M. (1996). Surfing the wave of national IT initiatives - Sweden and international policy diffusion. Information Technology Journal, 5, 191-205.

Kelegai, L. \& Middleton, M. (2000). Towards an information society: educating IT professionals in PNG. In Managing information technology in a global economy; 2001 Information Resources Management Association International Conference (pp. 1029-1031). Hershey, PA, USA: Idea Group, 2001.

Korpela, M. (1996). Traditional culture or political economy? On the root causes of organizational obstacles of IT in developing countries. Information Technology for Development Journal, 7, 29-42.

Landry, J.P., Longenecker, H.E., Haigood, B., \& Feinstein, D.L (2000). Americas Conference on Information Systems: AMCIS 2000. [CD-ROM] Long Beach: AMCIS.

Leitheiser, L. R. (1992). MIS skills for the 1990s: a survey of MIS manager perceptions. Journal of Management Information Systems, 9, 69-91.

Letch, N., \& Randolph, C. (2000). Do the skills of non-IT business graduates overlap with those of IT specialists? In Americas Conference on Information Systems: AMCIS 2000. Long Beach, CA, USA: AMCIS. (AMCIS2000 Proceedings, CDROM, 2000).

Loh, L., Sankar, C. S., \& Yeong, W. (1995). Job orientation, perceptions, and satisfaction: a study of information technology professionals in Singapore. Journal of Information \& Management, 29, 239-250.

Mestre, L. (2000). Improving computer-use success for students of diverse backgrounds. Knowledge Quest, 28, 5, 20-30.

Morris, M.G., \& Bartczak, S.A (2000). IT Skills in the public sector: comparing the views of middle managers and their supervisors. Americas Conference on Information Systems: AMCIS 2000. [CD-ROM] Long Beach: AMCIS.

Pham, B. (1997). The changing curriculum of computing and information technology in Australia. In ACSE '97: Proceedings of the second Australasian Conference on Computer Science Education (pp. 149-154). Retrieved $6^{\text {th }}$ March, 2001 from ACM Digital Library portal on the World Wide Web http://portal.acm.org/portal.cfm

Porter, M. (1985). Competitive advantage: creating and sustaining superior performance. New York: Free Press.

Rodriguez, M.V.R., \& Ferrante, A.J. (1996). Information technology for the 21st century: managing the change. Southampton, UK: Computational Mechanics

Salt, N. (1988). Employer perceptions. Lae, PNG: Papua New Guinea University of Technology (unpublished report).

Sinebare, M. (1999). Private computer training in Papua New Guinea: from chaos to order. Unpublished doctoral dissertation, University of Wollongong, Australia.

Snoke, R. \& Underwood, A. (1998). Generic attributes of IS graduates - a Queensland study. Proceedings $9^{\text {th }}$ Australasian Conference on Information Systems. Sydney: UNSW.

Talbert-Johnson, C., \& Beran, D. (1999). Higher education and teacher immediacy: creating dialogue for effective intercultural communication. Journal for a Just and Caring Education, 5, 4, 430-441.

Thoeuri, P. M., \& Gunn, R. (1998). Accounting information systems course structure and employers skills expectation. Journal of Accounting Education, 16, 101-121. 
Von Hellens, L. Wong, S., \& Orr, J. (2000). IT skills requirements: perspective from industry. In Proceedings $11^{\text {th }}$ Australasian Conference on Information Systems: ACIS 2000. Brisbane: ACIS. (ACIS2000 Proceedings, CD-ROM, 2000).

Waieng, P. (2000). Lets put PNG on the Net: Waieng. The PNG National. Retrieved $12^{\text {th }}$ June 2000 from the World Wide Web http://www.wr.com.au/national/000612nl.htm

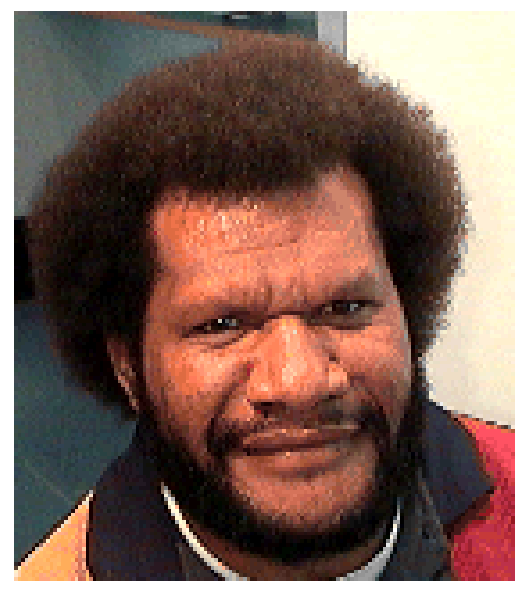

\section{Biographies}

Limbie Kelegai is a doctoral candidate with the Information Systems Management Research Centre (ISMRC) at Queensland University of Technology (QUT), Brisbane. His research interests are in the areas of information management, IT/IS curriculum and education, information and communication technology adoption and implementation in developing countries, information process and information policy and management. He obtained his Bachelors degree in Information Systems in 1983 at the PNG University of Technology. In 1995 he completed his Masters in Information Technology from QUT.

Prior to the doctoral program he was a Computer Manager with the Information Technology Services at the PNG University of Technology in Papua New Guinea.

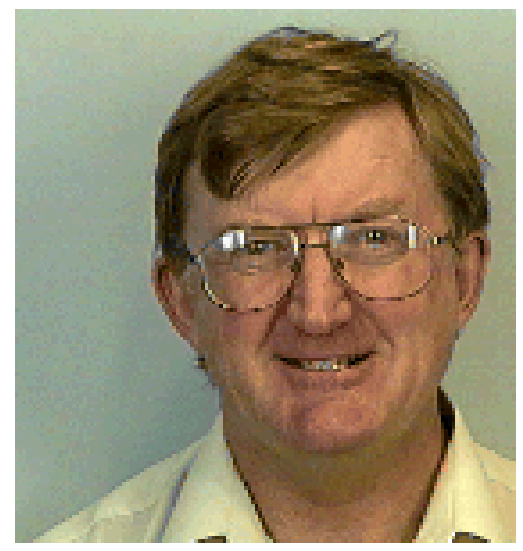

Michael Middleton is in the School of Information Systems at Queensland University of Technology and with the ISMRC. His research interests include information policy, information retrieval and library systems, and information management. He has written widely in these areas, including a book Information Management about to be published by Charles Sturt University Centre for Information Studies. 